\title{
On the Path of College Students' Mental Health under the Internet Plus
}

\author{
Haizhao Li \\ Shandong Technology and Business University \\ Yantai, Shandong, 264005
}

\begin{abstract}
Today, the information technology grows faster than ever before. The popularity of the Internet has brought unprecedented experiences to people. However, many college students cannot use the network properly while enjoying the convenience and pleasure brought by the Internet age, which seriously affects the students' academic performance, and mental health as there emerge "phubber", "game addition", "anxiety" and "phone freak". "Internet plus" can promote the uniqueness of mental health education, promote the standardization of mental health education, promote the self-growth of individual students, and promote the gridding of mental health education. Based on that, this article fully demonstrated the new opportunities brought by the "internet plus" to college students' mental health education, optimized the mental health education network platform through online and offline cooperation; created a sound atmosphere to actively carry out network quality education for college students; strengthened network supervision to create a positive network environment; launched special activities to generate a healthy positive atmosphere on campus; cultivated first-class teams to better control online psychology te aching; strengthe ned cooperation mechanis ms, and constructed student-family-school interactive education model. All these measures that contribute to exploring a path suitable for current students' mental health education are of great significance to help college students correctly use network tools, create healthy lifestyles, rationally plan university life, and become qualified builders and successors of socialist cause.
\end{abstract}

Keywords-internet plus; psychological health; methods; healthy lifestyle

\section{INTRODUCTION}

In the Internet age, mobile phone has become the first choice for people to access information. According to the survey, the majority of network users is mobile phone netizens in China. The popularity of smart phones has promoted fundamental changes in the media, and promoted the interconnection of living circles and friend circles. In particular, the application of online media tools like WeChat, Weibo and QQ enriches the information of college students, expands the horizon of the activity platform, expands the cognitive channels of college students, and provides more channels of emotional catharsis.

The Internet and smartphones also have a negative impact on the mental health of college students. The entertainment and convenience of them take up a lot of students' time, which also causes the long-term dependence on mobile phones called "mobile phone anxiety." If students over-use, or even rely on mobile phones for a long time, they will lose interests in study or life, or become hard to think independently, research and analyze. And sociophobia, "communication depression", "selfautism" etc. may ensue. Bad information on mobile phones also erodes the students' minds and lowers the moral baseline of college students. Students who are unable to distinguish them go astray, and even make illegal acts.

\section{Opportunities for College Mental Health EDUCATION AGAINST THE BACKDROP OF "INTERNET PLUS"}

\section{A. The uniqueness of "internet plus" can promote the effectiveness of mental health education}

The "Internet +" era brings the equality and interaction between individuals. Anyone can express themselves in their own way, and the inferiority and embarrassment caused by face-to-face communication will no longer exist as the boundaries of identity have gradually blurred. Every people has the right to show their own problems and opinions, or to provide psychologically confused people with solutions, which helps others raise questions, also helps provide psychological counseling for respondents in the first time. At the same time, psychological education workers can timely and effectively deliver the content of education or answers to problems in a timely and effective way, which is more conducive to solving problems, making mental health education more direct and effective [1].

\section{B. "Internet plus" convenience can promote the standardization of mental health education}

The advent of the Internet era has increased the intensity of data integration, and made it easier for psychologists to realize one-to-one, one-to-many sharing and communication. Through communication, according to the situation and characteristics of the respondents, we can timely review and retrieve similar cases, or find the best solution more effectively, and solve the problem more accurately. Furthermore, the convenience of the Internet also helps psychological educators to broadcast, interact with students, and share cases through the Internet, setting a platform for college mental health education that is more acceptable to students. In this platform, students with similar psychological problems can share cases and appropriate and effective methods will be provided timely to promote the universality and standardization of psychological education. 


\section{C. "Internet plus" autonomy can promote individual self- growth}

The Internet era provides each participant with a free and personalized stage where they can find friends of mutual interests, pursue various activities they like, record their moods and daily experiences. Everyone participate can find the "private customization" that suits themselves. College students can acquire, publish, exchange, and share news through various channels. They can also confide, express, and show their hobbies, and display their individuality. It will help them to pay attention to outside world, and contact the society so as to discover their own deficiencies by combining with their own characteristics and the needs of the society, and then make changes. That will make individuals calmer, confident, and prepared to meet the new environment and contribute to their growth.

\section{The gridding of "internet plus" can promote the full coverage of mental health education.}

The characteristics of the Internet are change, diversity, and novelty. In the virtual Internet model, it becomes common that everyone is a participant in cyberspace with the boundary between the superiority and the inferiority blurring. The equality of the identity is conducive to the expressions from both sides on a certain issue. People can also put their own confusion anonymously, and different groups provide various solutions to the problem, which is more helpful to solve the problem. Also, the Internet offers a variety of novel and personalized projects that can attract a large number of participants, in which the benign interaction between teachers and students is carried out in a timely and effective manner, and the problem is solved in the interaction. In addition, the great memory of the Internet can promptly locate students with mental health problems, and adopt different solutions according to different stages, ages and problems, and save the history to effectively track these students. Thus we can say the internet goes through whole process of psychological education.

\section{Exploration of NeW WAys of College Mental HEALth EDUCATION AgAinst THE BACKDROP OF "INTERNET PLUS"}

The internet plus is a double-edged sword for it not only rejuvenates the psychological education idea, but also broadens the boundary of the education and generates the discourse system, thus further strengthening the paradigm of psychological health education in university and colleges. Therefore, the psychology educators need to adapt to the trends followed by internet plus, complete the form of new psychological education methods within the internet by optimizing internet education, improving students' quality, enhancing supervision, launching characteristic activities, constructing an organic education system with students, family and school as a whole.

\section{A. Combine online and offline to optimize the mental health education network platform}

The internet becomes an essential part of people's life as it changes the ways of communication, pulls people together and make the interactions both online and offline more frequent. WeChat moment, Weibo and QQ live show that satisfy students' curiosity and desire to explore are enjoyed by students and become the necessity and top choice for daily exchanges and communication. "Amid the explosive information flow, the possibility of college students being exposed to mental health concepts, knowledge, and solutions is much greater [2].” Therefore, we must keep eye on the actual needs of students, make good use of campus network, campus official account, campus Baidu forum, campus radio and other means both online and offline to optimize mental health education network platform. "Organize the excellent mental health teachers to answer questions for college students on the network platform”. Through the online and offline ways, we can timely carry out teacher-student interaction, answer questions, and further guides college students to gain more mental health knowledge, clarify the importance of mental health education, and correctly solve their own mental health problems.

\section{B. Create a clear space and carry outnetwork quality education for college students}

The new media tools represented by smart phones bring convenience of communication and entertainment, which greatly facilitates students' learning, entertainment, communication, etc., but also brings disadvantages, such as addiction to mobile entertainment, games, occupying a large amount of daily time. Many students that cannot help themselves out from web addiction lose interests in learning, resulting in the ruin of their studies. Since there are many traps on the network, students who lack of vigilance cannot distinguish it so they are naturally the prey of them [3]. Again, the existence of bad information on the Internet has greatly affected the normal life of students. Therefore, it is important to build a healthy network environment and improve the network quality of college students. We must reasonably guide college students to do a good job in college career planning, use mobile phones reasonably and rationally, and strike a balance between entertainment and learning so that they can enjoy the happiness brought by new online media. We also need to guide students to be vigilant, learn to protect themselves, and identify network traps so as to avoid unnecessary harm. Students should be guided to make healthy use of the network, correctly use the new media to obtain information, and to be high-quality netizens, and contribute to the cyberspace that is civilized and comfortable.

\section{Strengthen network supervision and create a positive network environment}

Strengthening network supervision is conducive to reducing mental health problems caused by web addition. We must start from two aspects. For those who are less selfdisciplined, long-term indulging in games, entertainment, we must adopt strict supervision through talks and interactions lest they abandon studies, feel lonely and anxiety, social degradation. In this way, we can let them recognize the dangers, and arouse attention, so that they can rationally plan time, control themselves on online game entertainment, regain confidence and reinvent themselves, find the way forward. Moreover, it is necessary to strengthen the supervision of 
network public opinion, timely respond to the network public opinion incidents brought about by the web addiction, and carry out education guidance to reduce the negative impact to a minimum, so as to avoid causing greater harm. We must make clean the network environment, and filter network spam, etc., to create a positive network atmosphere for college students, and minimize the negative mental health impact of the network.

\section{Host characteristic events to create a healthy and sunny campus atmosphere}

Based on the new experience brought by the popularity of the Internet, college mental health education can use this carrier to actively create an experience activity suitable for contemporary college students to participate in, in order to guide them to pay attention to mental health, care for their own body and mind and maintain a right view of the convenience and experience brought by the network. We can take a moth to carry out network mental health culture on a regular basis, and set various forms of programs with a wide range of participation, such as psychological lecturing, emotional talks, mental health DV contests, emotional psychology salons, mental health videos, and other activities to make good use of network in popularizing mental health knowledge. In addition, we can also open online mental health classes, psychological interaction forums, lecturing, common psychological problems solving, college students' love concept and other courses. We can take the form of online live, online communication, online counseling to mobilize student and answering their questions. What's more, we can also set up an online psychological counseling workstation to list the common problems of students so that everyone can find solutions with ease. Based on the convenience of the network and the privacy of the personal space, we can establish an online peer exchange center where students can pose problems in time and avoid the embarrassment caused by face-to-face communication.

\section{E. Cultivate first-class teams and enhance the ability to harness online psychology}

To carry out the mental health education of college students against the Internet plus background, it is necessary to build a specialized, sophisticated and high-level team. "Strengthen the team building in the age mix, academic level, theoretical level, professional skills and other aspects to achieve a balanced combination. [4]" How to effectively apply the internet which is special and virtual to solve the psychological problems faced by students is worth to be considered by every mental health worker. Build a high-level network mental health education team, get familiar with the network platform to carry out the mental health education, know well the network mental health education discourse, innovate the teaching form, create a network mental health space, and win the trust and love of students. In addition, mental health educators can't sit still and rest on their laurels, instead, they must keep up with the pace of the times, pay attention to the new terminology, information, system, diversification, intensify learning to improve themselves, so as to build the network communication platform to provide help for students.

\section{F. Strengthen cooperation among students, families and schools}

The establishment of a complete mental health network system requires the support of the school, and it is inseparable from the participation of students and the cooperation of the family. Facing the impact and challenges brought by the Internet, it is particularly important to strengthen the cooperation mechanism and build a student-family-school interactive education model. When students are trapped in various psychological problems caused by indulging in the network, the school needs to understand the current situation of students, offer humanistic care, provide timely and necessary help to them, and deliver feedback and communicate with parents. As for parents, after receiving the notification from the school, we must maintain close contact with the school and care students and solve the psychological problems of students through conversations. Students themselves must plan their university life reasonably. They should properly use online entertainment and games. When problems arise again, they must face up to their own problems correctly and actively treat them with the help of psychological counselors.

\section{CONCLUSION}

The popularity of new media facilitates new experience, which is both the opportunity and challenge for mental instructors. To cope with it properly, they need to take measures to integrate traditional mental health education and information technology and make the education appealing and adapt to the trend. They also need to improve themselves to better rein the internet and analyze and solve problems among students. Amid the new situation, a first-class teaching group of internet mental health should be built. Strengthen the education mechanism to mobilize school, family and students themselves to form a positive interaction in education system.

\section{REFERENCES}

[1] Wang Zihua, Li Hui, Zhang Huimin. Network Approach to Mental Health Education of College Students in the internet plus [J] Education Forum, 2018,(03): 38.

[2] Zheng Hangyue. Constructing a New Way of Mental Health Education under the Network Environment [J] Journal of Qiqihar Junior Teachers' College, 2018,(01): 5-6.

[3] Li Tao, Cui Can, Li Li.The Influence of Mobile Media on the Study and Life of College Students-Taking North China Electric Power University as an Example [J]. The Guide of Science \& Education, 2014, (34):217.

[4] Li Haizhao. On 90s College Students' Behavior Characteristics and Mental Health Education Strategies [J] Journal of Changchun University, 2014, (03): 114-116. 